\title{
In Vivo Measures of Dopaminergic Radioligands in the Rat Brain: Equilibrium Infusion Studies
}

\author{
MICHAEL R. KILBOURN,* PHILLIP S. SHERMAN, AND KYLE KUSZPIT \\ Division of Nuclear Medicine, Department of Radiology, University of Michigan Medical School, \\ Ann Arbor, Michigan 48109
}

\begin{abstract}
KEYWORDS transporter; dopamine; vesicular monoamine; carbon radioisotopes
ABSTRACT The application of an equilibrium infusion method for measuring specific in vivo radioligand binding in the conscious rat brain was evaluated for two ligands of the dopaminergic system, $(+)-\alpha-\left[{ }^{11} \mathrm{C}\right]$ dihydrotetrabenazine (DTBZ) and $d$-threo$\left[{ }^{11} \mathrm{C}\right]$ methylphenidate (MePhen). Both radioligands can be successfully utilized to reach equilibrium distributions in rat brain within $1 \mathrm{~h}$; combinations of tritiated and carbon11-labeled radiotracers can furthermore be used to obtain simultaneous measures of the neuronal membrane dopamine transporter (using $\left[{ }^{3} \mathrm{H}\right] \mathrm{MePhen}$ ) and vesicular monoamine transporter (using $\left[{ }^{11} \mathrm{C}\right] \mathrm{DTBZ}$ ) in the same animal. These studies provided quantitative measures of distribution volume ratios, which represent specific radioligand binding. Stereospecificity of in vivo binding was demonstrated using equilibrium infusions of the low-affinity isomers of each ligand, $(-)-\alpha-\left[{ }^{11} \mathrm{C}\right]$ dihydrotetrabenazine (DTBZ) and $l$-threo- $\left[{ }^{11} \mathrm{C}\right]$ methylphenidate, both of which produced uniform brain distributions and no specific binding. Specific binding of $(+)-\alpha-\left[{ }^{11} \mathrm{C}\right]$ dihydrotetrabenazine was blocked by co-infusion of tetrabenazine, but was unaffected by administration of methylphenidate, haloperidol, or apomorphine. Specific binding of $d$-threo- $\left[{ }^{11} \mathrm{C}\right]$ methylphenidate, conversely, was blocked with unlabeled methylphenidate but not affected by tetrabenazine or the dopamine receptor ligands. Equilibrium measures of in vivo radioligand binding, as utilized in this study, offer a quantitative means to evaluate acute and chronic drug effects on in vivo radioligand binding in the rat brain. Synapse 43: 188-194, 2002. ๑ 2002 Wiley-Liss, Inc.
\end{abstract}

\section{INTRODUCTION}

In recent years there have been significant advances in our understanding of the structure and functioning of the transporters for neurotransmitters, particularly the neuronal membrane and vesicular transporters for the monoamines (Olivier et al., 2000). Alterations in the number or functioning of these neurotransmitter transporters, and the relationships between them, may be important parts of such diverse human health problems as neurodegeneration, drug abuse, and psychiatric diseases. With the availability of in vitro methods utilizing cloned and expressed transporters and animal models of altered levels of these transporters (Gainetdinov et al., 1999), one can expect more advances to be made in our knowledge of the role of these proteins in normal and diseased brain function. Even more exciting is the potential of taking this basic biochemical knowledge to the living human patient, using in vivo imaging methods such as positron emission tomography (PET) (Brooks, 1997; Stoessl and Ruth, 1998) and single photon emission computed tomography (SPECT) (Kugaya et al., 2000) measures of transporter numbers or functions.

Many research groups have investigated in vivo radioligand methods for studying the neuronal membrane dopamine transporter (DAT) (Carroll et al., 1995). Less effort has been devoted to the vesicular monoamine transporter (VMAT2), partly due to the more limited selection of potential radioligands, but a successful in vivo radioligand for this transporter is also now available (Kilbourn, 1994). The availability of these radioligands provides opportunities to examine neurochemistry in intact animal models, particularly

\footnotetext{
Contract grant sponsor: the National Institutes of Health; Contract grant numbers: MH47611, NS 15655; Contract grant sponsor: the Department of Energy; Contract grant sponsor: DEFG-02-87ER60561.

*Correspondence to: Michael R. Kilbourn, Ph.D., Division of Nuclear Medicine, 3480 Kresge III Bldg., University of Michigan, Ann Arbor, MI 48109.

E-mail: mkilbour@umich.edu

Received 11 March 2001; Accepted 31 October 2001
} 
in rodents where neurotoxin, surgical, or genetic models of numerous neurological diseases are currently available or actively being developed. In vivo studies of radioligand binding to DAT or VMAT2 would also permit evaluation of recently described mechanisms for phosphorylation-dependent regulation of transporter functions (Pristupa et al., 1998; Reith and Chen, 1997). Methods for using in vivo radiotracers in rodents vary widely, including 1) very simple determinations of radioactivity concentrations at a single time point after administration, 2) construction of tissue time-activity curves using groups of animals at distinct time points, and 3) attempts to define the time-dependent regional brain pharmacokinetics using small animal imaging devices. Whereas the last approach would provide information most like that obtained in humans using PET or SPECT imaging studies, small animal imaging devices with the needed resolution and sensitivity (Hume et al., 1998) are as yet not widely available. Ex vivo measures of regional brain tissue radioactivity concentrations at multiple distinct time points, using groups of animals, combined with pharmacokinetic analysis of the extrapolated time-dependent distributions offers an intermediate method for performing such in vivo animal studies, but that is a time- and resource-intensive process requiring large numbers of animals to accurately define the radiotracer pharmacokinetics. The simplest technique available is the bolus injection of a radiotracer and determination of regional brain distributions at a single time point selected to represent a steady state or transient equilibrium; specific binding is then estimated as the simple ratio of radioactivity in one region over a second region selected as representing nonspecific binding. However, this approach may not be appropriate when radioligands do not reach an equilibrium distribution within the experimental time period (Gatley et al., 2000).

As an alternative to bolus injections, we and others (Endres and Carson, 1998; Kilbourn and Sherman, 1997) have investigated the application of an infusion to equilibrium approach to radiotracer administrations; regional brain distributions of radioactivity need be determined at only one time point after equilibrium is reached, simplifying the method and minimizing the requirement for large numbers of animals. At equilibrium the relative concentrations of radioactivity between regions of the brain remains constant and the determination of regional brain concentrations and blood concentrations of authentic radiotracer allows simple calculation of the regional distribution volumes (termed DV or $\mathrm{V}_{\mathrm{d}}$ ) for the radiotracer. Furthermore, the use of a region with minimal specific binding allows calculation of regional distribution volume ratios (DVR) (Carson, 2000; Logan, 2000) and the regional binding potentials $(\mathrm{BP}=\mathrm{DVR}-1)$. The infusion protocol in animals thus appears particularly appealing and can provide essentially the same estimates of specific binding generated by imaging studies of radiotracers in the human brain.

We have previously reported the application of the infusion to equilibrium approach to in vivo quantification of $(+)-\alpha-\left[{ }^{3} \mathrm{H}\right]$ DTBZ binding to the VMAT2 in rat brain (Kilbourn and Sherman, 1997). Although a large number of radioligands have been developed for in vivo studies of the dopamine receptors and the neuronal membrane transporter for dopamine (DAT), the equivalent equilibrium infusion approach in small animals has not been applied to those ligands. We report here the 1) evaluation of infusion to equilibrium methods in conscious rats for the DAT radioligand $d$-threo- $\left[{ }^{3} \mathrm{H}\right]$ methylphenidate ( $\left.\left.\left[{ }^{3} \mathrm{H}\right] \mathrm{MePhen}\right) ; 2\right)$ comparison of specific binding estimates from bolus infusion, single time point studies with the equilibrium-derived binding potentials for $\left[{ }^{3} \mathrm{H}\right] \mathrm{MePhen}$ and $(+)-\alpha-\left[{ }^{11} \mathrm{C}\right] \mathrm{DTBZ}$; and 3$)$ development and application of dual equilibrium infusion radiotracer methods for simultaneous measurement of $d$-threo- $\left[{ }^{3} \mathrm{H}\right] \mathrm{MePhen}(\mathrm{DAT})$ and $(+)-\alpha-\left[{ }^{11} \mathrm{C}\right]-$ DTBZ (VMAT2) radioligand binding.

\section{MATERIALS AND METHODS Drugs and radiochemicals}

d-threo- $\left[{ }^{3} \mathrm{H}\right]$ Methylphenidate $\left(\left[{ }^{3} \mathrm{H}\right] \mathrm{MePhen}\right.$; specific activity $83 \mathrm{Ci} / \mathrm{mmol}$ ) was prepared (Amersham, Arlington Heights, IL, USA) by a two-step synthesis involving $\left[{ }^{3} \mathrm{H}\right]$ methylation of a suitably protected ritalinic acid precursor, following the procedure used for synthesis of $d$-threo-[ $\left[{ }^{11} \mathrm{C}\right]$ methylphenidate (Ding et al., 1994). The $d$-threo- and $l$-threo-isomers of $\left[{ }^{11} \mathrm{C}\right]$ methylphenidate (specific activities $>500 \mathrm{Ci} / \mathrm{mmol}$ ) were prepared by $\left[{ }^{11} \mathrm{C}\right]$ methylation of the appropriate ritalinic acid precursors followed by deprotection. The (+)- and (-)isomers of $\alpha-\left[{ }^{11} \mathrm{C}\right]$ dihydrotetrabenazine (specific activities $>500 \mathrm{Ci} / \mathrm{mmol})$ were prepared by $\left[{ }^{11} \mathrm{C}\right]$ methylation of the corresponding 9-O-desmethyl precursors, by methods previously described (Jewett et al., 1997). Tetrabenazine was obtained from ICN Biomedicals (Aurora, IL, USA) and methylphenidate hydrochloride, apomorphine, and haloperidol were obtained from Research Biochemicals (Natick, MA, USA). All drugs and radiotracers were administered as solutions in isotonic saline.

\section{Radiotracer and drug administration protocols}

All studies were done in Sprague-Dawley CD rats (150-200 g; Charles Rivers, Portage, MI, USA). Under sodium pentobarbital anesthesia, the animals were prepared for intravenous radiotracer injections by incision of the skin and insertion of a catheter into one or both femoral veins. The incisions were then closed and the animal placed in a plastic restrainer tube and allowed to awaken; all studies were done using animals 
TABLE I. Regional radioactivity concentration ratios for isomers of $\alpha$-dihydrotetrabenazine (DTBZ) in rat brain

\begin{tabular}{|c|c|c|c|c|c|c|c|}
\hline \multirow[b]{2}{*}{ Radioligand } & \multirow[b]{2}{*}{ Protocol } & \multirow[b]{2}{*}{$N$} & \multirow[b]{2}{*}{ Drug } & \multirow[b]{2}{*}{ Striatum } & \multicolumn{3}{|c|}{ Tissue/cortex } \\
\hline & & & & & Hypothalamus & Hippocampus & Thalamus \\
\hline$(+)-\left[{ }^{11} \mathrm{C}\right] \mathrm{DTBZ}$ & bol, $30 \mathrm{~min}$ & 8 & None & $4.12 \pm 0.39$ & $1.93 \pm 0.12$ & $0.94 \pm 0.08$ & $0.95 \pm 0.07$ \\
\hline$(+)-\left[{ }^{3} \mathrm{H}\right] \mathrm{DTBZ}$ & bol, $15 \mathrm{~min}$ & 6 & None & $3.35 \pm 0.09$ & $2.64 \pm 0.27$ & $1.28 \pm 0.03$ & $1.53 \pm 0.11$ \\
\hline$(+)-\left[{ }^{11} \mathrm{C}\right] \mathrm{DTBZ}^{1}$ & inf, $60 \mathrm{~min}$ (control) & 11 & None & $2.79 \pm 0.17$ & $1.52 \pm 0.22$ & $0.90 \pm 0.05$ & $0.87 \pm 0.06$ \\
\hline$(-)-\left[{ }^{11} \mathrm{C}\right] \mathrm{DTBZ}$ & inf, $60 \mathrm{~min}$ & 4 & None & $0.98 \pm 0.01 *$ & $0.87 \pm 0.10^{*}$ & $0.95 \pm 0.03$ & $0.92 \pm 0.08$ \\
\hline$(+)-\left[{ }^{11} \mathrm{C}\right] \mathrm{DTBZ}^{1}$ & inf, $60 \mathrm{~min}$ & 8 & MePhen & $2.99 \pm 0.17$ & $1.52 \pm 0.22$ & $0.90 \pm 0.05$ & $1.02 \pm 0.30$ \\
\hline$(+)-\left[{ }^{11} \mathrm{C}\right] \mathrm{DTBZ}^{1}$ & inf, $60 \mathrm{~min}$ & 8 & TBZ & $0.98 \pm 0.11^{*}$ & $0.87 \pm 0.10^{*}$ & $0.95 \pm 0.03$ & $0.83 \pm 0.02$ \\
\hline$(+)-\left[{ }^{11} \mathrm{C}\right] \mathrm{DTBZ}^{1}$ & inf, $60 \mathrm{~min}$ & 4 & Haloperidol & $3.13 \pm 0.29$ & $1.29 \pm 0.07$ & $0.93 \pm 0.04$ & $0.95 \pm 0.07$ \\
\hline$(+)-\left[{ }^{11} \mathrm{C}\right] \mathrm{DTBZ}^{1}$ & inf, $60 \mathrm{~min}$ & 8 & Apomorphine & $2.56 \pm 0.32$ & $1.14 \pm 0.12$ & $0.92 \pm 0.10$ & $0.91 \pm 0.14$ \\
\hline
\end{tabular}

Determined following either bolus injection (bol) or administration using a programmed bolus + constant infusion (inf) protocol. Methylphenidate (MePhen) and tetrabenazine (TBZ) were co-infused with radiotracer and haloperidol and apomorphine administered 30 min prior. Tissue/cortex ratios determined following the infusion protocol represent equilibrium distribution volume ratios (DVR). Data are shown as mean $\pm \mathrm{SD}$.

${ }^{1}$ Studies performed using dual radiotracer infusions.

$* P<0.005$ vs control $(+)-\left[{ }^{11} \mathrm{C}\right] \mathrm{DTBZ}$ infusion study.

in the fully awake but restrained state. Drugs or saline (controls) injections were done via the femoral vein catheter. Radiotracer injections were done through the femoral vein catheters using a Harvard programmable infusion pump. Bolus administrations were done using a 1-min infusion of radiotracer in a volume of $1 \mathrm{~mL}$. Equilibrium infusion studies were performed using a bolus administration of $66.6 \%$ of the dose $(1 \mathrm{~mL})$ over a 1-min period, followed by constant infusion of the remaining $33.3 \%(0.5 \mathrm{~mL})$ of the dose over the remaining $59 \mathrm{~min}$ (for 1-h infusion studies) or $119 \mathrm{~min}$ (2-h infusion studies).

Groups of 2-4 animals were used at a single experimental session and experiments repeated to achieve the group sizes shown in Table I. At designated times after initial bolus or infusion of radiotracers, animals were killed by i.v. injection of an overdose of sodium pentobarbital and the brain rapidly removed and dissected according to a slight modification of a literature method (Glowinski and Iversen, 1966) into samples of striatum, cortex, hippocampus, hypothalamic region, thalamus, pons/medulla, and cerebellum. Tissue samples were then weighed and counted: carbon-11 was determined immediately using an automated $\gamma$ counter. Tissue solubolizer was added and after digestion (2-3 days) scintillation fluid was added and the sample counted for tritium (automatic $\beta$-counter). Data were calculated as percent injected dose/gram tissue $(\% \mathrm{ID} / \mathrm{g})$.

For all studies the specific binding was estimated by calculating the concentration ratios of regions of interest to cortex as the reference region. For infusion studies, this measure is termed the distribution volume ratio (DVR).

\section{Statistics}

Comparisons between groups were evaluated either with a Student $t$-test or with a repeated measures ANOVA. A level of $P<0.05$ was considered significant.

\section{RESULTS \\ Single radiotracer studies $(+)-\alpha-\left[{ }^{11} \mathrm{C}\right]$ dihydrotetrabenazine $\left((+)-\alpha-\left[{ }^{11} \mathbf{C}\right] \mathrm{dtbz}\right)$}

The regional brain distribution of radioactivity after bolus and equilibrium administration of $(+)-\alpha-\left[{ }^{3} \mathrm{H}\right]-$ DTBZ has been previously reported (Kilbourn and Sherman, 1997). In this study, we compared the regional brain distribution of the carbon-11-labeled tracer at a longer time point after bolus administration (30 min) with that obtained using infusion to equilibrium. Use of the longer time point for sampling after bolus injection produces an even larger bias in the estimates of specific binding, as the striatum/cortex ratio significantly exceeds the value obtained at equilibrium (Table I) and is higher than obtained at $15 \mathrm{~min}$ (Kilbourn and Sherman, 1997). Using either the 30min bolus sampling point or infusion to equilibrium method; however, highest concentrations of the radioligand can be clearly demonstrated in both the striatum and the hypothalamic region.

\section{$(-)-\alpha-\left[{ }^{11} \mathrm{C}\right]$ dihydrotetrabenazine $\left((-)-\alpha-\left[{ }^{11} \mathrm{C}\right] \mathrm{dtbz}\right)$}

The bolus + infusion administration of $(-)-\alpha-$ $\left[{ }^{11} \mathrm{C}\right] \mathrm{DTBZ}$, the inactive isomer $\left(K_{i}=4\right.$ micromole: Kilbourn et al., 1995) produced a nearly uniform brain distribution of radioactivity, with no evidence for specific binding in any region (Table I).

\section{d-threo- $\left[{ }^{3} \mathbf{H}\right]$ methylphenidate}

The regional brain distribution of $d$-threo- $\left[{ }^{3} \mathrm{H}\right] \mathrm{Me}-$ Phen was determined at 30 min following bolus administration and after 30 or 60 min of a bolus + infusion protocol (Table II). In a separate experiment, the regional distribution of radioactivity was also determined using infusion of the carbon-11-labeled radiotracer. Distribution volume ratios for the infusion studies were equivalent for all three groups, with specific binding only detected in the striatum; in contrast to the results with DTBZ, the bolus administration of $d$-threo$\left[{ }^{3} \mathrm{H}\right] \mathrm{MePhen}$ and sampling at $30 \mathrm{~min}$ provided a striatum/cortex ratio more similar to that obtained using 
TABLE II. Regional radioactivity concentration ratios for isomers of methylphenidate (MePhen) in rat brain

\begin{tabular}{|c|c|c|c|c|c|c|c|}
\hline \multirow[b]{2}{*}{ Radioligand } & \multirow[b]{2}{*}{ Protocol } & \multirow[b]{2}{*}{$N$} & \multirow[b]{2}{*}{ Drug } & \multirow[b]{2}{*}{ Striatum } & \multicolumn{3}{|c|}{ Tissue/cortex } \\
\hline & & & & & Hypothalamus & Hippocampus & Thalamus \\
\hline d-threo- $\left[{ }^{3} \mathrm{H}\right] \mathrm{MePhen}$ & bol, $30 \mathrm{~min}$ & 8 & None & $1.76 \pm 0.17$ & $0.86 \pm 0.05$ & $0.99 \pm 0.08$ & - \\
\hline d-threo- $\left[{ }^{3} \mathrm{H}\right] \mathrm{MePhen}$ & inf, $30 \mathrm{~min}$ & 8 & None & $1.61 \pm 0.06$ & $0.91 \pm 0.07$ & $1.00 \pm 0.05$ & $0.77 \pm 0.06$ \\
\hline d-threo- $\left[{ }^{3} \mathrm{H}\right] \mathrm{MePhen}^{1}$ & inf, $60 \mathrm{~min}$ (control) & 7 & None & $1.54 \pm 0.13$ & $0.85 \pm 0.13$ & $1.01 \pm 0.16$ & $0.64 \pm 0.08$ \\
\hline d-threo- $\left[{ }^{11} \mathrm{C}\right] \mathrm{MePhen}$ & inf, $60 \mathrm{~min}$ & 4 & None & $1.54 \pm 0.06$ & $0.87 \pm 0.02$ & $0.96 \pm 0.02$ & $0.73 \pm 0.03$ \\
\hline l-threo- $\left[{ }^{11} \mathrm{C}\right] \mathrm{MePhen}$ & inf, $60 \mathrm{~min}$ & 4 & None & $1.04 \pm 0.01^{*}$ & $0.95 \pm 0.03$ & $1.03 \pm 0.01$ & $0.87 \pm 0.01$ \\
\hline d-threo- $\left[{ }^{3} \mathrm{H}\right] \mathrm{MePhen}^{1}$ & inf, $60 \mathrm{~min}$ & 8 & MePhen & $0.99 \pm 0.04^{*}$ & $0.87 \pm 0.08$ & $1.01 \pm 0.06$ & $0.62 \pm 0.04$ \\
\hline d-threo- $\left[{ }^{3} \mathrm{H}\right] \mathrm{MePhen}^{1}$ & inf, $60 \mathrm{~min}$ & 8 & TBZ & $1.53 \pm 0.14$ & $0.78 \pm 0.06$ & $0.96 \pm 0.03$ & $0.75 \pm 0.05$ \\
\hline d-threo- $\left[{ }^{3} \mathrm{H}\right] \mathrm{MePhen}^{1}$ & inf, $60 \mathrm{~min}$ & 4 & Haloperidol & $1.65 \pm 0.13$ & $0.84 \pm 0.08$ & $1.10 \pm 0.03$ & $0.83 \pm 0.03$ \\
\hline$d$-threo- $\left[{ }^{3} \mathrm{H}\right] \mathrm{MePhen}^{1}$ & inf, $60 \mathrm{~min}$ & 8 & Apomorphine & $1.61 \pm 0.13$ & $0.85 \pm 0.04$ & $1.01 \pm 0.03$ & $0.71 \pm 0.03$ \\
\hline
\end{tabular}

Determined following either bolus injection (bol) or administration using a programmed bolus + constant infusion (inf) protocol. Methylphenidate (MePhen) and tetrabenazine (TBZ) were co-infused with radiotracer and haloperidol and apomorphine administered 30 min prior. Tissue/cortex ratios determined following the infusion protocol represent equilibrium distribution volume ratios (DVR). Data are shown as mean \pm SD.

infusion protocol represent equilibrium distribution vol
${ }^{1}$ Studies performed using dual radiotracer infusions.

$* P<0.005$ vs control $d$-threo- $\left[{ }^{3} \mathrm{H}\right] \mathrm{MePhen}$ infusion study.

the constant infusion protocol. The regional distributions of radioactivity were identical after 30 and $60 \mathrm{~min}$ of infusion, supporting that equilibrium distribution of the radiotracer had been reached by $60 \mathrm{~min}$ (or likely earlier).

\section{l-threo- $\left[{ }^{3} \mathbf{H}\right]$ methylphenidate}

Equilibrium infusion of the low-affinity l-threo$\left[{ }^{11} \mathrm{C}\right] \mathrm{MePhen}$ gave a uniform distribution of radioactivity with no evidence of specific binding in the striatum (Table II).

\section{Dual radiotracer studies}

Regional distribution volume ratios for $(+)-\alpha-$ $\left[{ }^{11} \mathrm{C}\right] \mathrm{DTBZ}$ and $d$-threo- $\left[{ }^{3} \mathrm{H}\right] \mathrm{MePhen}$ were next determined using a dual-radiotracer infusion protocol. In control studies $(n=4)$, tissue concentrations and distribution volume ratios for both radiotracers were essentially identical to those obtained in the prior single radiotracer studies.

Significant and essentially complete reductions in striatal and hypothalamic DVR were obtained for (+)$\alpha-\left[{ }^{11} \mathrm{C}\right] \mathrm{DTBZ}$ with coadministration of tetrabenazine (Table I), with tissue distribution volume ratios identical to those found with the inactive (-)-isomer. Prior administration of tetrabenazine, however, had no effect on the equilibrium distribution of $d$-threo- $\left[{ }^{3} \mathrm{H}\right] \mathrm{MePhen}$ (Table II). Pretreatment of rats with methylphenidate produced the opposite results, no effect on equilibrium $(+)-\alpha-\left[{ }^{11} \mathrm{C}\right]$ DTBZ distribution (Table I) but a significant reduction of $d$-threo- $\left[{ }^{3} \mathrm{H}\right] \mathrm{MePhen}$ binding in the striatum (Table II).

Using the dual radiotracer infusion protocol, no significant effects of a dopamine receptor antagonist (haloperidol) or agonist (apomorphine) on the equilibrium distribution of $d$-threo- $\left[{ }^{3} \mathrm{H}\right] \mathrm{MePhen}$ and $(+)-\alpha-\left[{ }^{11} \mathrm{C}\right]-$ DTBZ could be demonstrated.

\section{DISCUSSION}

The in vivo infusion to equilibrium method for determination of regional specific binding in rat brain has been evaluated for two radioligands currently in clinical use for the study of the dopaminergic system: $d$-threo- $\left[{ }^{11} \mathrm{C}\right]$ methylphenidate (MePhen) and $(+)-\alpha-$ $\left[{ }^{11} \mathrm{C}\right]$ dihydrotetrabenazine (DTBZ). In prior bolus studies in animals and humans, it was apparent that these ligands show readily reversible binding brain with pharmacokinetics suitable for an infusion to equilibrium study design and such infusion protocols have been reported in rats and humans for $(+)-\alpha-\left[{ }^{11} \mathrm{C} /\right.$ ${ }^{3}$ H]DTBZ (Kilbourn and Sherman, 1997; Koeppe et al., 1997). In this study, we have demonstrated that d-threo- $\left[{ }^{11} \mathrm{C}\right] \mathrm{MePhen}$ is also a very good radioligand for this approach to quantification of in vivo regional binding in rodent brain. As there are reported significant effects of common anesthetics on in vivo radiotracer distributions all studies were performed in the awake rat brain.

\section{Regional brain distributions of radioligands}

Following either bolus administration or use of a bolus + infusion protocol, both radioligands produced a heterogeneous regional brain distribution of radioactivity, with highest concentrations found in the striatum; this is consistent with the known distribution of the DAT and the VMAT2 and similar to previous bolus studies using (+)- $\alpha-\left[{ }^{3} \mathrm{H}\right] \mathrm{DTBZ}$ (Kilbourn and Sherman, 1997) and d-threo- $\left[{ }^{3} \mathrm{H}\right] \mathrm{MePhen}$ (Ding et al., 1994; Gatley et al., 1995). For $(+)-\alpha-\left[{ }^{11} \mathrm{C}\right] \mathrm{DTBZ}$, there is an intermediate concentration of radioactivity in the hypothalamic region, reflecting the binding of the radioligand to the VMAT2 in the serotonergic and adrenergic neurons located in that region of the brain. For $d$-threo- $\left[{ }^{3} \mathrm{H}\right] \mathrm{MePhen}$, which is more specific for the dopaminergic neurons, no significant concentration of radioligand is noted in any other brain region than the striatum. With both radioligands, equilibrium infusion of the low-affinity stereoisomer $\left((-)-\alpha-\left[{ }^{11} \mathrm{C}\right] \mathrm{DTBZ}\right)$, $K_{i}=4 \mathrm{mmol}$; $l$-threo- $\left[{ }^{11} \mathrm{C}\right] \mathrm{MePhen}, \mathrm{IC}_{50}=540 \mathrm{nM}$ (Gatley et al., 1996)) produced uniform brain distributions and tissue concentration ratios near unity. 
The calculation of distribution volume ratios from the infusion studies requires reaching an equilibrium of tissue radioactivity concentrations and selection of an appropriate brain region for use as an estimate of nonspecific binding. We had previously demonstrated that $\alpha-(+)-\left[{ }^{3} \mathrm{H}\right] \mathrm{DTBZ}$ reached equilibrium by $60 \mathrm{~min}$ of infusion (Kilbourn and Sherman, 1997). In this study the equilibrium for $d$-threo- $\left[{ }^{3} \mathrm{H}\right] \mathrm{MePhen}$ was also clearly reached within this time frame, as the values for striatum/cortex (and striatum/cerebellum, data not shown) at $30 \mathrm{~min}$ were indistinguishable from those obtained at $60 \mathrm{~min}$. For both $(+)-\alpha-\left[{ }^{11} \mathrm{C}\right] \mathrm{DTBZ}$ and $d$-threo- $\left[{ }^{3} \mathrm{H}\right] \mathrm{MePhen}$ we have evaluated using either the cerebellum or the cortex and the region of nonspecific binding. For both radioligands there is minimal specific binding in either region and as the cortex is the brain region we and others have utilized for in vivo imaging studies of these radioligands in human brain (Frey et al., 1996; Lee et al., 2000), it was chosen in this study. Using the same reference region for both radiotracers minimizes the experimental errors introduced in tissue dissection and counting from a dual-radiotracer infusion protocol. $(+)-\alpha-\left[{ }^{11} \mathrm{C}\right] \mathrm{DTBZ}$ shows higher specific binding in the striatum as compared to $\left[{ }^{3} \mathrm{H}\right] \mathrm{Me}-$ Phen, but both radiotracers have binding potentials $(\mathrm{BP}=\mathrm{DVR}-1)$ in the striatum which are within the range suggested as suitable for measurements of changes of in vivo radioligand binding due to physiological or pharmacological challenges (Endres and Carson, 1998).

The use of a bolus injection of radiotracer, followed by determination of regional brain concentrations of radioactivity at a single time point, certainly offers a simpler experimental protocol for estimating specific binding. Most often, ratios between brain regions are calculated at 1) the point of greatest difference between the region of interest and a region purportedly void of specific binding sites, or 2) at a time point occurring within a time span when the ratios between tissues are fairly steady. The estimated specific binding for $(+)-\alpha-$ $\left[{ }^{11} \mathrm{C}\right] \mathrm{DTBZ}$ and $d$-threo- $\left[{ }^{3} \mathrm{H}\right] \mathrm{MePhen}$ determined here following bolus injection can be compared to the equivalent values determined by infusion studies (Tables I, II). The choice of a time point for tissue analysis is crucial. For d-threo- $\left[{ }^{3} \mathrm{H}\right] \mathrm{MePhen}$ the distribution volume ratio estimated at $30 \mathrm{~min}$ after the bolus injection is similar to that determined using the equilibrium infusion method, but the choice of time for measurement remains critical as the striatum/cerebellum ratio clearly changes with time after a bolus administration (Gatley et al., 1995; Kilbourn and Sherman, unpublished data). For $(+)-\alpha-\left[{ }^{11} \mathrm{C}\right] \mathrm{DTBZ}$, however, the specific binding estimate following the bolus injection was higher than determined using the equilibrium approach and the difference is consistently seen with sacrifice times chosen at both the peak striatal uptake (15 min, DVR = $3.76 \pm 0.15$; Kilbourn and Sherman,
1997) and a later time point (30 min, this study). Thus, the use of the bolus injection with a single time point measurement of concentrations should be made with caution and with an understanding of these possible limitations.

\section{Pharmacological specificity}

Using the dual infusion of $d$-threo- $\left[{ }^{3} \mathrm{H}\right] \mathrm{MePhen}$ and $(+)-\alpha-\left[{ }^{11} \mathrm{C}\right] \mathrm{DTBZ}$, the effects of three types of dopaminergic drugs were examined. Co-injection of tetrabenazine, the specific and high-affinity inhibitor of the VMAT2, completely eliminated specific binding of (+)$\alpha-\left[{ }^{11}\right.$ C $]$ DTBZ in the striatum and hypothalamus, but did not affect the in vivo binding of $d$-threo- $\left[{ }^{3} \mathrm{H}\right] \mathrm{Me}-$ Phen. Conversely, coadministration of methylphenidate essentially completely reduced the specific binding of $d$-threo- $\left[{ }^{3} \mathrm{H}\right] \mathrm{MePhen}$, but had no effect on $(+)-\alpha-$ $\left[{ }^{11} \mathrm{C}\right] \mathrm{DTBZ}$ binding. These results were expected, as each of these two drugs have been shown to be specific for one type of transporter.

Administration of the dopamine receptor antagonist (haloperidol) or agonist (apomorphine) had no significant effect on either (+)- $\alpha-\left[{ }^{11} \mathrm{C}\right] \mathrm{DTBZ}$ or d-threo$\left[{ }^{3} \mathrm{H}\right] \mathrm{MePhen}$ specific binding in any region of the rat brain. These studies with a dopaminergic receptor ligand also demonstrate the lack of effect of changes in blood flow on the equilibrium radiotracer measures, since such drugs are known to significantly alter regional cerebral blood flow rates in the rat brain (Ingvar et al., 1983; McCulloch and Teasdale, 1979).

The lack of effect of methylphenidate or dopamine receptor ligands on the in vivo binding of $(+)-\alpha-$ $\left[{ }^{11} \mathrm{C}\right] D T B Z$ agrees with prior studies which have failed to demonstrate regulation of the VMAT2 binding site in the dopaminergic neurons of the rat striatum (by such drugs as dopamine receptor ligands, dopamine reuptake inhibitors, L-DOPA, or monoamine oxidase A inhibitors) (Wilson and Kish, 1996; Naudon et al., 1994; Vander Borght et al., 1995). Our results do not match those of Fleckenstein and co-workers, who recently reported a modest $(20 \%)$ cocaine-induced increase in binding of $\left[{ }^{3} \mathrm{H}\right] \mathrm{DTBZ}$ in purified rat brain synaptic vesicles (Brown et al., 2000), an effect also observed for dopamine transporter inhibitors such as amfonelic acid and GBR 12935. Methylphenidate, used in this experiment, is an effective inhibitor of the DAT and produces rapid changes in dopamine levels in the rat brain (Gatley et al., 1999), but in our experiments it did not alter in vivo radioligand binding to the VMAT2. The explanation for these divergent results may be due simply to different drug effects (methylphenidate vs. cocaine) or the difference between in vitro studies (Brown et al., 2000) and our in vivo studies; even for in vitro assays, divergent results using radioligand binding of $\left[{ }^{3} \mathrm{H}\right] \mathrm{DTBZ}$ have been reported, depending on the tissue preparation (Hogan et al., 2000). 
Since TBZ rapidly and effectively depletes brain tissues of dopamine (Kuszenski, 1977), as evidenced by increased in vivo $\left[{ }^{11} \mathrm{C}\right] \mathrm{RAC}$ binding (Dewey et al., 1993), the lack of effect of TBZ on $d$-threo- $\left[{ }^{3} \mathrm{H}\right] \mathrm{MePhen}$ binding would support the prior conclusions (Gatley et al., 1995) that this radioligand is not sensitive in vivo to acute changes of endogenous levels of dopamine. The lack of acute effects of dopaminergic drugs (other than methylphenidate itself) on in vivo binding of this radioligand also suggests that occupation of dopamine receptors does not induce rapid $(<1 \mathrm{~h})$ changes in the binding of radioligands to the transporter; such lack of effects of dopamine receptor agonists and antagonists have been reported with other DAT radioligands such as $\left[{ }^{11} \mathrm{C}\right] \mathrm{CFT}$ and $\left[{ }^{125} \mathrm{I}\right] \mathrm{RTI}-55$ (Cline et al., 1992; Scheffel et al., 1996). However, it has been recently reported that stimulants such as amphetamine, and more importantly dopamine itself, induce a rapid internalization of transporter protein in hDAT-expressing cell lines (Saunders et al., 2000), resulting in a rapid loss of DA uptake. As haloperidol and tetrabenazine should have had significant effects on dopamine release and turnover, the in vivo and in vitro data may not be in agreement. It is not known if the radioligand employed in our in vivo studies, $d$-threo- $\left[{ }^{3} \mathrm{H}\right] \mathrm{MePhen}$, is capable of binding to transporters which have been trafficked to cytosolic sites; in that case, the in vivo measures would simply be insensitive to the differential location of DAT at cell surface vs. internal sites. Further studies in this area are needed to understand the potential for in vivo radioligands to measure the proportions of transporters in different physical environments.

Finally, these studies provide some insight into the importance of specific activity for in vivo radiotracer studies and the potential for application of this technique to studies utilizing small animal PET imaging devices. Most of the equilibrium infusion studies performed here utilized 4-6 $\mathrm{mCi}$ of total carbon-11labeled radiotracer. For methylphenidate, using a specific activity of approximately $500 \mathrm{Ci} / \mathrm{mmol}$ at time of beginning the infusion and a molecular weight of $233 \mathrm{~g} / \mathrm{mol}$, this calculates to a total injected mass of nearly $2 \mu \mathrm{g}$ for a $4 \mathrm{mCi}$ infusion. Infusion studies with the tritiated radioligand employed a total of $10 \mu \mathrm{Ci}$ per animal; at a specific activity of 83 $\mathrm{Ci} / \mathrm{mmol}$, that is an injected dose of $0.027 \mu \mathrm{g}$. Despite a mass dose difference of 75 , the carbon-11 and tritium-labeled radioligands provided equivalent in vivo regional brain distributions and estimates of specific binding. This provides encouragement that sufficient amounts of carbon-11-labeled tracers should be tolerated in future in vivo imaging studies in rats and the use of the equilibrium infusions provide an excellent approach to quantification of specific binding.

\section{ACKNOWLEDGMENTS}

The authors thank Drs. Kirk Frey and Robert Koeppe for many helpful discussions.

\section{REFERENCES}

Brooks DJ. 1997. Advances in imaging Parkinson's disease. Curr Opin Neurol 10:327-331.

Brown JM, Hanson GR, Fleckenstein AE. 2000. The vesicular monoamine transporter-2: a novel site of cocaine action. Soc Neurosci Abstr 26:795.

Carroll FI, Scheffel U, Dannals RF, Boja JW, Kuhar MJ. 1995. Development of imaging agents for the dopamine transporter. Med Res Rev 15:419-444.

Carson RE. 2000. PET physiological measurements using constant infusion. Nucl Med Biol 27:657-660.

Cline EJ, Scheffel U, Boja JW, Mitchell WM, Carroll FI, Abraham P, Lewin AH, Kuhar MJ. 1992. In vivo binding of $\left[{ }^{125} \mathrm{I}\right] \mathrm{RTI}-55$ to dopamine transporters: pharmacology and regional distribution with autoradiography. Synapse 12:37-46.

Dewey SL, Smith GS, Logan J, Brodie JD, Fowler JS, Wolf AP. 1993. Striatal binding of the PET ligand ${ }^{11} \mathrm{C}$-raclopride is altered by drugs that modify synaptic dopamine levels. Synapse 13:350-356.

Ding YS, Fowler JS, Volkow ND, Gatley SJ, Logan J, Dewey SL, Alexoff D, Fazzini E, Wolf AP. 1994. Pharmacokinetics and in vivo specificity of $\left[{ }^{11} \mathrm{C}\right] \mathrm{dl}$-threo-methylphenidate for the presynaptic dopaminergic neuron. Synapse 18:152-160.

Endres CJ, Carson RE. 1998. Assessment of dynamic neurotransmitter changes with bolus or infusion delivery of neuroreceptor ligands. J Cereb Blood Flow Metab 18:1196-1210.

Frey KA, Koeppe RA, Kilbourn MR, Vander Borght TM, Albin RL, Gilman S, Kuhl DE. 1996. Presynaptic monoamine vesicles in Parkinson's disease and normal aging. Ann Neurol 40:873-884

Gainetdinov RR, Jones SR, Caron MG. 1999. Functional hyperdopaminergia in dopamine transporter knock-out mice. Biol Psychiatry 46:303-311.

Gatley SJ, Ding YS, Volkow ND, Chen R, Sugano Y, Fowler JS. 1995. Binding of d-threo- $\left[{ }^{11} \mathrm{C}\right]$ methylphenidate to the dopamine transporter in vivo: insensitivity to synaptic dopamine. Eur J Pharmacol 281:141-149.

Gatley S, Volkow ND, Gifford AN, Fowler JS, Dewey SL, Ding YS Logan J. 1999. Dopamine-transporter occupancy after intravenous doses of cocaine and methylphenidate in mice and humans. Psychopharmacology 146:93-100.

Gatley SJ, Gifford AN, Carroll FI, Volkow ND. 2000. Sensitivity of binding of high-affinity dopamine receptor radioligands to increased synaptic dopamine. Synapse 38:483-488.

Glowinski, Iversen LL. 1966. Regional studies of catecholamines in the rat brain. I. The disposition of $\left[{ }^{3} \mathrm{H}\right]$ norepinephrine, $\left[{ }^{3} \mathrm{H}\right] \mathrm{dopa}-$ mine and $\left[{ }^{3} \mathrm{H}\right]$ dopamine in various regions of the brain. $J$ Neurochem 13:655-669.

Hogan KA, Staal RG, Sonsalla PK. 2000. Analysis of VMAT2 binding after methamphetamine or MPTP treatment: disparity between homogenates and vesicle preparations. J Neurochem 74:2217-2220.

Hume SP, Gunn RN, Jones T. 1998. Pharmacological constraints associated with positron emission tomographic scanning of small laboratory animals. Eur J Nucl Med 25:173-176.

Ingvar M, Lindvall O, Stenevi U. 1983. Apomorphine-induced changes in local cerebral blood flow in normal rats and after lesions of the dopaminergic nigrostriatal bundle. Brain Res 262:259-265.

Jewett DM, Kilbourn MR, Lee LC. 1997. A simple synthesis [ $\left.{ }^{11} \mathrm{C}\right]$ dihydrotetrabenazine. Appl Radiat Isot 24:197-199.

Kilbourn MR. 1994. PET radioligands for vesicular neurotransmitter transporters. Med Chem Res 5:113-126.

Kilbourn M, Sherman P. 1997. In vivo binding of $(+)-\alpha-\left[{ }^{3} \mathrm{H}\right]$ dihydrotetrabenazine to the vesicular monoamine transporter of rat brain: bolus vs. equilibrium studies. Eur J Pharmacol 331:161-168.

Kilbourn MR, Sherman PS, Pisani T. 1992. Repeated reserpine administration reduces in vivo $\left[{ }^{18} \mathrm{~F}\right] \mathrm{GBR} 13119$ binding to the dopamine uptake site. Eur J Pharmacol 216:109-112

Kilbourn MR, Lee L, Vander Borght T, Jewett D, Frey K. 1995. Binding of $(\alpha)$-dihydrotetrabenazine to the vesicular monoamine transporter is stereospecific. Eur J Pharmacol 278:249-252.

Koeppe RA, Frey KA, Kume A, Albin R, Kilbourn MR, Kuhl DE. 1997. Equilibrium versus compartmental analysis for assessment of the vesicular monoamine transporter using $(+)-\alpha-\left[{ }^{11} \mathrm{C}\right]$ dihydrotetrabenazine (DTBZ) and PET. J Cereb Blood Flow Metab 17:919-931.

Kuczenski R. 1977. Differential effects of reserpine and tetrabenazine on rat striatal synaptosomal dopamine biosynthesis and synaptosomal dopamine pools. J Pharmacol Exp Ther 201:357-367. 
Kugaya A, Fujita M, Innis RB. 2000. Applications of SPECT imaging of dopaminergic neurotransmission in neuropsychiatric disorders. Ann Nucl Med 14:1-9.

Lee CS, Samii A, Sossi V, Ruth TJ, Schulzer M, Holden JE, Wudel J, Pal PK, de la Fuente-Fernandez R, Calne DB, Stoessl AJ. 2000. In vivo positron emission tomographic evidence for compensatory changes in presynaptic dopaminergic nerve terminals in Parkinson's disease. Ann Neurol 47:493-503.

Logan J. 2000. Graphical analysis of PET data applied to reversible and irreversible tracers. Nuc Med Biol 27:661-666.

McCulloch J, Teasdale G. 1979. Effects of apomorphine upon local cerebral blood flow. Eur J Pharmacol 55:99-102.

Naudon L, Leroux-Nicollet I, Costentin J. 1994. Short-term treatments with haloperidol or bromocriptine do not alter the density of the monoamine vesicular transporter in the substantia nigra. Neurosci Lett 173:1-4.

Olivier B, Soudijn W, van Wijngaarden I. 2000. Serotonin, dopamine and norepinephrine transporters in the central nervous system and their inhibitors. Prog Drug Res 54:59-119.

Pristupa ZB, McConkey F, Liu F, Man HY, Lee FJ, Wang YT, Niznik HB. 1998. Protein kinase-mediated bidirectional trafficking and functional regulation of the human dopamine transporter. Synapse 30:79-87.
Reith ME, Chen NH. 1997. Pharmacology and regulation of the neuronal dopamine transporter. Eur J Pharmacol 324:1-10.

Saunders C, Ferrer JV, Shi L, Chen J, Merrill G, Lamb ME, LeebLundberg LM, Carvelli L, Javitch JA, Galli A. 2000. Amphetamineinduced loss of human dopamine transporter activity: an internalization-dependent and cocaine-sensitive mechanism. Proc Natl Acad Sci USA 97:6850-6855.

Scheffel U, Steinert C, Kim SE, Ehlers MD, Boja JW, Kuhar MJ. 1996. Effect of dopaminergic drugs on the in vivo binding of $\left[{ }^{3} \mathrm{H}\right]$ WIN 35,428 to central dopamine transporters. Synapse 23:6169.

Stoessl AJ, Ruth TJ. 1998. Neuroreceptor imaging: new developments in PET and SPECT imaging of neuroreceptor binding (including dopamine transporters, vesicle transporters and post synaptic receptor sites). Curr Opin Neurol 11:327-333.

Vander Borght TM, Kilbourn MR, Desmond TJ, Kuhl DE, Frey KA. 1995. The vesicular monoamine transporter is not regulated by dopaminergic drug treatments. Eur J Pharmacol 294:577-583.

Wilson JM, Kish SJ. 1996. The vesicular monoamine transporter, in contrast to the dopamine transporter, is not altered by chronic cocaine self-administration in the rat. J Neurosci 16: $3507-3510$ 